\title{
Decreased soluble RAGE in neutrophilic asthma is correlated with disease severity and RAGE G82S variants
}

\author{
YANHUA LYU ${ }^{1,2^{*}}$, HAIJIN ZHAO ${ }^{1 *}$, YANMEI YE ${ }^{1}$, LAIYU LIU ${ }^{1}$, \\ SHUNFANG ZHU ${ }^{1}$, YANG XIA ${ }^{1}$, FEI ZOU ${ }^{3}$ and SHAOXI CAI ${ }^{1}$ \\ ${ }^{1}$ Chronic Airways Diseases Laboratory, Department of Respiratory and Critical Care Medicine, Nanfang Hospital, \\ Southern Medical University, Guangzhou, Guangdong 510515; ${ }^{2}$ Department of Respiratory Diseases, \\ The People's Hospital of Zhongshan City, Zhongshan, Guangdong 528400; ${ }^{3}$ School of Public Health and \\ Tropical Medicine, Southern Medical University, Guangzhou, Guangdong 510515, P.R. China
}

Received January 16, 2017; Accepted November 13, 2017

DOI: $10.3892 / \mathrm{mmr} .2017 .8302$

\begin{abstract}
The advanced glycosylation end product-specific receptor (RAGE) has been demonstrated to be an important mediator of asthma pathogenesis. The soluble isoform of RAGE (sRAGE) acts as a 'decoy' to sequester RAGE ligands, and thus prevents their binding to the receptor. A number of reports have linked deficiency of sRAGE to the severity and outcomes of various human diseases, and association with RAGE G82S variants. However, whether sRAGE levels are increased or decreased in asthmatic patients is unclear. The aim of the present study was to determine plasma sRAGE levels in different asthma phenotypes and associations of plasma sRAGE levels with RAGE G82S variants. A total of 85 neutrophilic and 109 non-neutrophilic newly diagnosed asthmatic patients, and 118 healthy controls, were recruited. Plasma sRAGE levels were measured by ELISA analysis. RAGE G82S genotypes were detected using the Sanger sequencing method. Plasma sRAGE levels were decreased in
\end{abstract}

Correspondence to: Dr Shaoxi Cai, Chronic Airways Diseases Laboratory, Department of Respiratory and Critical Care Medicine, Nanfang Hospital, Southern Medical University, 1838 Guangzhou Da Dao Bei, Guangzhou, Guangdong 510515, P.R. China

E-mail: caishaox@fimmu.com

*Contributed equally

Abbreviations: RAGE, advanced glycosylation end product-specific receptor; sRAGE, soluble advanced glycosylation end product-specific receptor; esRAGE, endogenous secretory advanced glycosylation end product-specific receptor; cRAGE, cleaved advanced glycosylation end product-specific receptor; AGE, advanced glycosylation end product; HMGB1, high mobility group protein $\mathrm{B} 1$; FEV1, forced expiratory volume in $1 \mathrm{sec}$; COPD, chronic obstructive pulmonary disease; BMI, body mass index; SAA, serum amyloid A; SNP, single nucleotide polymorphism

Key words: sRAGE, G82S variant, asthma, inflammatory phenotype neutrophilic asthmatics $(443.67 \pm 208.9 \mathrm{pg} / \mathrm{ml})$ and increased in non-neutrophilic asthmatics $(677.63 \pm 300.75 \mathrm{pg} / \mathrm{ml})$ compared with healthy controls $(550.02 \pm 300.83 \mathrm{pg} / \mathrm{ml})(\mathrm{P}<0.001)$. Plasma sRAGE levels were positively correlated with FEV1\% predicted $(\mathrm{FEV} 1 \%$ Pre $)\left(\mathrm{r}_{\mathrm{p}}=0.258 ; \mathrm{P}=0.023\right)$ in neutrophilic asthmatics. The frequency of G82S genotypes was significantly different between neutrophilic and non-neutrophilic asthmatics $(\mathrm{P}=0.009)$. Neutrophilic asthmatics with genotypes A/G or A/A $(389.83 \pm 150.37$ and $264.59 \pm 161.74 \mathrm{pg} / \mathrm{ml}$, respectively) had significantly decreased sRAGE levels compared with the $\mathrm{G} / \mathrm{G}$ genotype $(498.64 \pm 235.37 \mathrm{pg} / \mathrm{ml})(\mathrm{P}=0.022)$. Those with the A/G and A/A genotype $(60.14 \pm 22.36 \%)$ displayed a trend toward lower FEV1\% Pre compared with those with the G/G genotype $(64.51 \pm 27.37 \%)$. No significant difference in sRAGE levels or an association with FEV1\% Pre was observed between the different genotypes in non-neutrophilic asthmatics. In conclusion, the results of the present study indicated that plasma sRAGE levels are altered in different asthma inflammatory phenotypes. Plasma sRAGE may be a biomarker of asthma severity and may be associated with G82S gene variants in neutrophilic asthmatics.

\section{Introduction}

The advanced glycosylation end product-specific receptor (RAGE) is a single-transmembrane, multi-ligand receptor that belongs to the immunoglobulin superfamily. It was initially cloned in 1992 and termed receptor for advanced glycosylation end products (AGEs) of proteins (1).

The RAGE gene generates extensive splice variants in humans and other mammals $(2,3)$. In addition to the full-length RAGE, there are two major splice variants: Variant 1 (C-truncated RAGE) and variant 2 (N-truncated RAGE). N-truncation deletes the V-type domain, the ligand binding domain, from the full-length RAGE. C-truncation removes the transmembrane and $\mathrm{C}$-terminal domains of the full-length RAGE and contains only the extracellular domain of RAGE (2), rendering RAGE free (secreted) and soluble. One variant of soluble RAGE (sRAGE), endogenous secretory RAGE (esRAGE), also termed RAGE variant 1, is generated through alternative RNA splicing $(4,5)$. In humans, full-length 
RAGE is the most prevalent form of RAGE, followed by esRAGE, the most predominant soluble form of the sRAGE isoforms (2,5). In addition to alternative RNA splicing, sRAGE may be generated via proteolytic cleavage of the full-length RAGE $(6,7)$. This type of RAGE is termed cleaved RAGE (cRAGE). However, esR AGE and cRAGE are able to bind the same RAGE ligands, and are therefore functionally equivalent (5).

RAGE binds a variety of ligands, including AGEs, high mobility group protein B1 (HMGB1), serum amyloid A (SAA), and S100 family proteins (8-11). RAGE is highly expressed in normal lungs, particularly in alveolar epithelial type I cells, compared with other tissues $(12,13)$. A recent study demonstrated that the absence of RAGE abolished the majority of the typical pathological indicators of asthma, including airway hypersensitivity, eosinophilic inflammation and airway remodeling, in a house dust mite-RAGE knockout mouse model of asthma/allergic airway disease, suggesting that RAGE may be a principal mediator of asthma pathogenesis (14). In addition, increased expression of RAGE ligands in asthma has been reported, including HMGB1, SAA and S100 family proteins (8-11). Conceivably, suppression of RAGE activation and/or expression may be a promising approach to decrease the airway inflammation commonly observed in asthma.

sRAGE may act as a decoy receptor to compete with RAGE ligands for binding with the full-length RAGE, thereby suppressing the activation of RAGE at the cell surface (15). Accumulating evidence has demonstrated that sRAGE may be associated with various chronic diseases, including metabolic, cardiovascular, neurodegenerative and inflammatory disorders (16-19). Previous studies have demonstrated that sRAGE was decreased in patients with chronic obstructive pulmonary disease (COPD) and was correlated with the severity of emphysema and neutrophilic inflammatory conditions (20-25).

RAGE genetic variability additionally results from single-nucleotide polymorphisms (SNPs). A total of $>30$ SNPs have been identified within the RAGE gene and are associated with diabetes mellitus (26). Among these SNPs, RAGE genetic variation rs2070600 (Gly82Ser, G82S), which causes a glycine to serine substitution at amino acid number 82 of the ligand-binding V-domain (Gly82Ser) in the extracellular domain, is of particular interest, as it has been associated with circulating RAGE levels $(27,28)$ and COPD (21). In addition, genome-wide association studies have revealed an association between the Gly82Ser polymorphism and pulmonary function $(29,30)$.

However, to date, there have been few studies, which have examined the association between sRAGE and asthma. These studies had small sample sizes and their results were contradictory $(11,20,31)$. For example, Sukkar et al (20) reported that $\mathrm{SRAGE}$ was deficient in neutrophilic asthma. Other studies, however, reported elevated levels of sRAGE in asthmatics $(11,31)$. The potential reason for the discrepancy may be attributable to the fact that different asthma inflammatory phenotypes, which are classified as neutrophilic and non-neutrophilic based on induced sputum inflammatory cells (20), are associated with RAGE genetic variants.

Therefore, the primary purpose of the present study was to determine plasma sRAGE levels in asthmatics with different inflammatory phenotypes, correlate plasma sRAGE levels with related clinical characteristics, and assess the association between plasma sRAGE and the RAGE G82S genetic variant.

\section{Materials and methods}

Study population. A total of 96 patients were recruited from the outpatient clinic of Nanfang Hospital, Southern Medical University (Guangzhou, China), between September 2011 and September 2012, and 97 patients from The People's Hospital of Zhongshan City (Zhongshan, China) between September 2014 and December 2015. The characteristics of the subjects are displayed in Table I. All patients were $>18$ years old and newly-diagnosed with asthma via positive bronchodilator reversibility test or airway hyper-responsiveness to methacholine. A positive bronchodilator reversibility test is defined as an increase in forced expiratory volume in $1 \mathrm{sec}$ (FEV1) of $>12 \%$ and $>200 \mathrm{ml}$ from baseline, $10-15 \mathrm{~min}$ subsequent to the inhalation of $200-400 \mu \mathrm{g}$ albuterol or equivalent. Airway hyper-responsiveness to methacholine is defined as a decrease in FEV1 from baseline of $\geq 20 \%$ with standard doses of methacholine (32). As a control group, 118 healthy individuals without a history of chronic respiratory disease, allergies, cardiovascular disease, diabetes and neurological diseases, and without evidence of airflow obstruction measured by spirometry, were recruited between September 2014 and December 2015. The present study was approved by the Medical Ethics Committees of Nanfang Hospital and The People's Hospital of Zhongshan City. All subjects provided written informed consent for participation in the study.

Study design. All participants completed a questionnaire to collect data about age, sex, weight, height and smoking history. Nonsmokers were defined as those who had a $<2$-pack-year (pack-year, cigarette packs per day multiplied by the number of years smoking) smoking history during their lifetime, and had not smoked for at least 1 year prior to participation. Smokers were defined as having a smoking history of 2 pack-years or more. All participants received pulmonary function testing, sputum induction and collection of a 5-ml EDTA-preserved blood specimen following recruitment. All asthmatics were divided into a neutrophilic asthma group (neutrophils $\geq 65 \%$ ) and non-neutrophilic asthma group (neutrophils $<65 \%$ ) based on induced sputum inflammatory cells. This $65 \%$ cut-off value was selected according to a previous report (20).

Sample preparation and measurement of $S R A G E$. Blood collection and sputum induction and their processing were performed as per a previous report (8). Sputum smears in which the ratio of squamous epithelial cells/nuclear cells was $<20 \%$ were considered to be adequate specimens. Following processing of the blood samples, plasma was stored at $-80^{\circ} \mathrm{C}$ until use. Plasma sRAGE levels were detected by ELISA analysis using Quantikine sRAGE ELISA, (cat. no. DRG00; R\&D Systems, Inc., Minneapolis, MN, USA), according to the manufacturer's protocol. This ELISA kit measures the total pool of sRAGE, including esRAGE and cRAGE (2).

DNA preparation and genotype analyses of RAGE G82S. Genomic DNA was prepared from peripheral blood samples 
Table I. Subject characteristics.

\begin{tabular}{|c|c|c|c|c|}
\hline Characteristics & $\begin{array}{c}\text { Neutrophilic } \\
\text { asthmatics }(n=85)\end{array}$ & $\begin{array}{l}\text { Non-neutrophilic } \\
\text { asthmatics }(n=109)\end{array}$ & $\begin{array}{c}\text { Healthy } \\
\text { controls }(n=118)\end{array}$ & P-value \\
\hline Male/female, $\mathrm{n}$ & $61 / 47$ & $56 / 29$ & $76 / 42$ & 0.328 \\
\hline Age, $y$ & $46.26 \pm 14.86$ & $38.41 \pm 13.23^{\mathrm{a}}$ & $48.75 \pm 18.31$ & $<0.001$ \\
\hline $\mathrm{BMI}, \mathrm{kg} / \mathrm{m}^{2}$ & $22.35 \pm 3.26$ & $22.15 \pm 3.00$ & $21.78 \pm 2.56$ & 0.600 \\
\hline Smoker (yes/no) & $45 / 40$ & $44 / 65$ & $51 / 67$ & 0.196 \\
\hline FEV1\% Pre & $62.77 \pm 25.00$ & $67.11 \pm 24.06$ & $97.26 \pm 9.73^{a}$ & $<0.001$ \\
\hline Sputum eosinophils, \% & $2.5(9.5)$ & $15.5(28.8)^{\mathrm{a}}$ & $0(4.5)$ & $<0.001$ \\
\hline Sputum neutrophils, \% & $87.0(18.12)^{\mathrm{a}}$ & $41.5(20.5)$ & $46.0(54.0)$ & $<0.001$ \\
\hline
\end{tabular}

Data are presented as the mean \pm standard deviation, or the median (interquartile range). ${ }^{\mathrm{a}}<0.001$. BMI, body mass index; FEV1\% Pre, predicted forced expiratory volume in $1 \mathrm{sec}$.

using a pure gene DNA purification kit (Tiangen Biotech Co., Ltd., Beijing, China), according to the manufacturer's protocol. The RAGE SNP (rs2070600; G82S) was determined using the Sanger sequencing method by BGI (Shenzhen, China).

Statistical analysis. SPSS 16.0 software (SPSS, Inc., Chicago, IL, USA) was used for statistical analysis. Continuous variables were evaluated for a normal distribution using the Kolmogorov-Smirnov test. Parametric data are presented as mean \pm standard deviation. Categorical variables are presented as either medians (interquartile ranges) or numbers (percentages), as appropriate. Comparisons among groups were performed using one-way analysis of variance. For the post hoc multiple comparisons, least significant difference test was used when equal variances were assumed and Tamhane's T2 test was used when equal variances were not assumed. Categorical variables were examined using the $\chi^{2}$ test. Correlations were assessed using Spearman or Pearson rank correlation coefficients. The Hardy-Weinberg equilibrium of the G82S polymorphism was examined using the Executive SNP Analyzer 1.0 (BGI, Shenzhen, China). All statistical analyses were two-sided, and $\mathrm{P}<0.05$ was considered to indicate a statistically significant difference.

\section{Results}

Subject characteristics. A total of 194 newly-diagnosed asthmatics and 118 healthy controls were included in the analysis. Of the asthma patients, 85 were neutrophilic and 109 were non-neutrophilic. The characteristics of the subjects are displayed in Table I. There was no significant difference in sex, body mass index (BMI) and smoking history between asthmatic and control subjects. The mean age of the non-neutrophilic asthma group was lower compared with that of the neutrophilic and control groups. Asthmatics had a decreased FEV1\% predicted (FEV1\% Pre) compared with healthy controls, although there was no difference between the two asthma groups.

Plasma sRAGE levels. There was a significant difference in plasma sRAGE levels between asthmatic patients and normal controls $(\mathrm{F}=15.925 ; \mathrm{P}<0.001)$. The mean plasma sRAGE

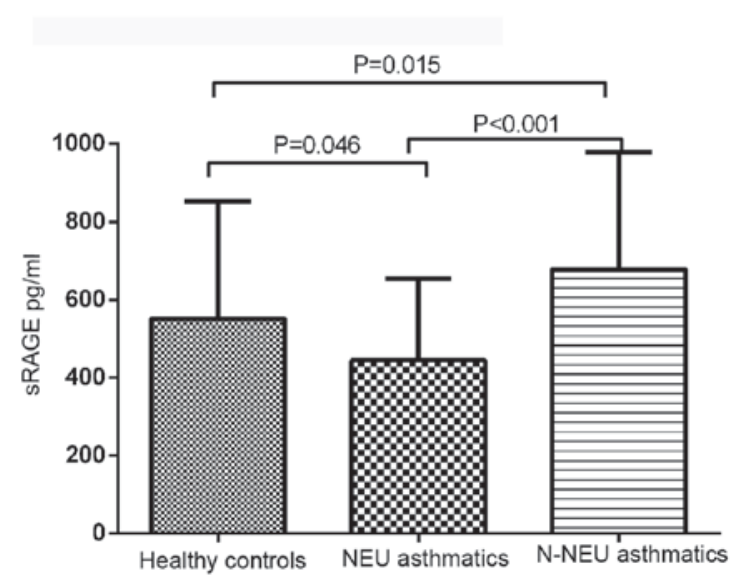

Figure 1. Comparison of plasma sRAGE levels in NEU asthmatics $(n=85)$, N-NEU asthmatics $(n=109)$ and healthy controls $(n=118)$. sRAGE, soluble advanced glycosylation end product-specific receptor; NEU, neutrophilic; N-NEU, non-neutrophilic.

level was significantly decreased in neutrophilic asthmatics $(443.67 \pm 208.9 \mathrm{pg} / \mathrm{ml})$ and increased in non-neutrophilic asthmatics $(677.63 \pm 300.75 \mathrm{pg} / \mathrm{ml})$, compared with the control group (550.02 \pm 300.83 pg/ml; Fig. 1).

Correlation of plasma sRAGE with clinical characteristics of asthmatic patients. The plasma sRAGE level of neutrophilic asthmatics was positively correlated with FEV1\% Pre $\left(r_{p}=0.258 ; P=0.023\right.$; Fig. $\left.2 \mathrm{~A}\right)$, while no significant correlation was observed in non-neutrophilic asthmatics $(\mathrm{P}=0.406)$. The plasma sRAGE level of non-neutrophilic asthmatics was inversely correlated with the percentage of sputum neutrophils $\left(r_{p}=-0.278 ; P=0.009\right.$; Fig. 2B), although no significant correlation was observed in neutrophilic asthmatics $(\mathrm{P}=0.183)$. There was no significant correlation between plasma sRAGE level and sex, BMI, age, smoking history or and FVC\% Pre, or the percentage of sputum eosinophils $(\mathrm{P}>0.05)$, in the two asthma groups.

Frequencies of RAGE G82S polymorphism. The RAGE G82S genotype distribution among neutrophilic asthmatics $(\mathrm{G} / \mathrm{G}$, $50.6 \% ; \mathrm{A} / \mathrm{G}, 45.9 \%$; A/A, 3.5\%), non-neutrophilic asthmatics 

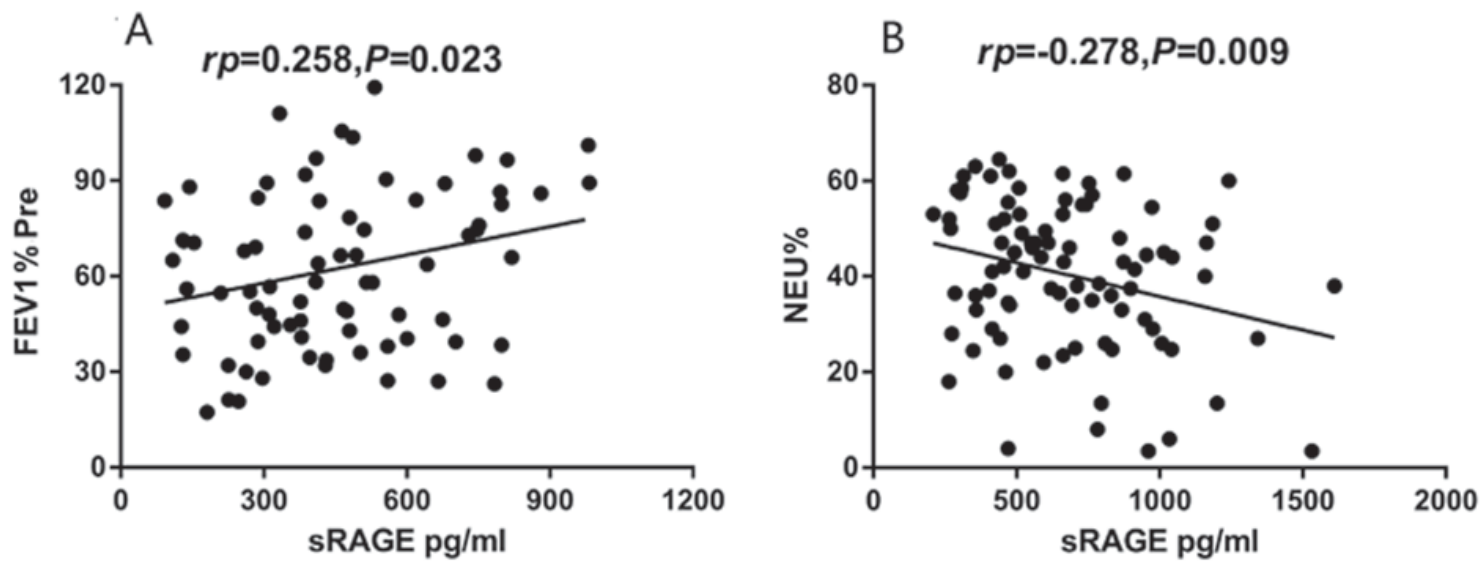

Figure 2. Correlations between plasma sRAGE and (A) FEV1\% Pre, and (B) NEU\%, in non-neutrophilic asthmatics (n=109). sRAGE, soluble advanced glycosylation end product-specific receptor; FEV1\% Pre, predicted forced expiratory volume in 1 sec; NEU\%, percentage of sputum neutrophils.

(G/G, 69.7\%; A/G, 24.8\%; A/A, 5.5\%), and controls (G/G, $69.5 \% ; \mathrm{A} / \mathrm{G}, 26.3 \% ; \mathrm{A} / \mathrm{A}, 4.2 \%)$ did not deviate significantly from Hardy-Weinberg equilibrium $\left(\chi^{2}=2.71, \mathrm{P}=0.100\right.$ $\chi^{2}=2.682, \mathrm{P}=0.102$; and $\chi^{2}=0.851, \mathrm{P}=0.356$, respectively) (Fig. 3). The frequency of the G82S genotype was significantly different between neutrophilic and non-neutrophilic asthmatics $\left(\chi^{2}=9.510, P=0.009\right)$, and between neutrophilic asthmatics and healthy controls $\left(\chi^{2}=8.441, \mathrm{P}=0.015\right)$, while no significant difference between non-neutrophilic asthmatics and healthy controls was noted $\left(\chi^{2}=0.238, P=0.888\right)$.

Association of RAGE G82S genotypes with plasma sRAGE and FEV1\% Pre. The present study analyzed the association between RAGE G82S genotypes and plasma sRAGE distribution (Fig. 4A), and demonstrated a significant association between G82S genotypes and plasma sRAGE levels in neutrophilic asthmatics. Following adjustment for age, subjects with the $\mathrm{G} / \mathrm{G}$ genotype exhibited a significantly increased sRAGE level $(498.64 \pm 235.37 \mathrm{pg} / \mathrm{ml})$ compared with those with the A/G genotype $(389.83 \pm 150.37 \mathrm{pg} / \mathrm{ml})$ and A/A genotype $(264.59 \pm 161.74 \mathrm{pg} / \mathrm{ml})(\mathrm{P}=0.022)$. Only 3 neutrophil subjects had an A/A genotype, and they had very low plasma sRAGE levels. Neutrophilic asthmatics with the RAGE A/G or A/A genotype displayed a trend toward lower FEV1\% Pre compared with those with the $\mathrm{G} / \mathrm{G}$ genotype $(60.14 \pm 22.36 \%$ vs. $64.51 \pm 27.37 \%$; Fig. 4B). However, significant differences in sRAGE between the different genotypes, and associations with FEV1\% Pre, were not observed in non-neutrophilic asthmatics and healthy controls.

\section{Discussion}

The present study demonstrated that plasma sRAGE levels were altered in different asthma inflammatory phenotypes. At initial diagnosis, plasma sRAGE levels were decreased in patients with neutrophilic asthma and increased in patients with non-neutrophilic asthma compared with healthy subjects. In addition, the plasma sRAGE level was positively correlated with FEV1\% Pre in neutrophilic asthmatics. In terms of G82S genotype, the frequencies of G82S genotypes were different between neutrophilic asthmatics and healthy controls. G82S genotype exhibited a trend that correlated with the severity of pulmonary dysfunction. To the best of our knowledge,

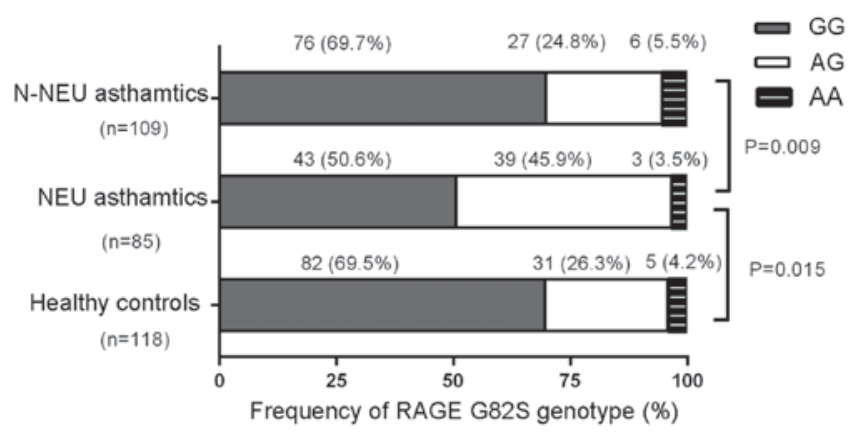

Figure 3. Frequencies of RAGE G82S genotypes in three groups of study subjects. RAGE, advanced glycosylation end product-specific receptor; NEU, neutrophilic; N-NEU, non-neutrophilic.

the present study was the first to report a likely association between RAGE G82S gene variants and plasma sRAGE levels in patients with asthma.

Few studies have examined sRAGE levels and asthma inflammatory phenotypes. In accordance with the results of the present study, Watanabe et al (11) reported elevated levels of sRAGE in the sputum of asthmatic patients. In that study, the subjects exhibited low levels of sputum neutrophils (median, 24\%; upper limit, 47\%), and high eosinophil counts (median, 9.4\%; lower limit, 4.5\%). However, Sukkar et al (20) reported that sRAGE was deficient in neutrophilic asthma, which is consistent with the results of the present study. Notably, the patients in the study of Sukkar et al (20) were clinically stable older asthmatics, and $68 \%$ of them used inhaled corticosteroids; in the present study, all the patients were newly-diagnosed asthmatics, suggesting that plasma sRAGE levels, although altered in different asthma inflammatory phenotypes, may remain relatively stable regardless of medical therapy. Similar to the findings adults $(7,11,16,20)$, Eli-Seify et al (33) reported that children with $>2 \%$ eosinophils and $\geq 40 \%$ neutrophils exhibited lower sRAGE levels compared with children with $>2 \%$ eosinophils and $<40 \%$ neutrophils; this suggests that the sRAGE level may remain relatively stable in different asthma inflammatory phenotypes regardless of age.

Previous studies have demonstrated that decreased plasma levels in sRAGE were associated with increased progression 
A

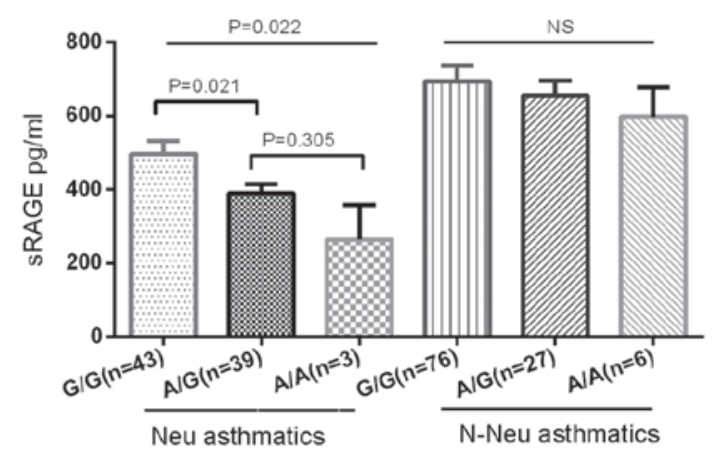

B

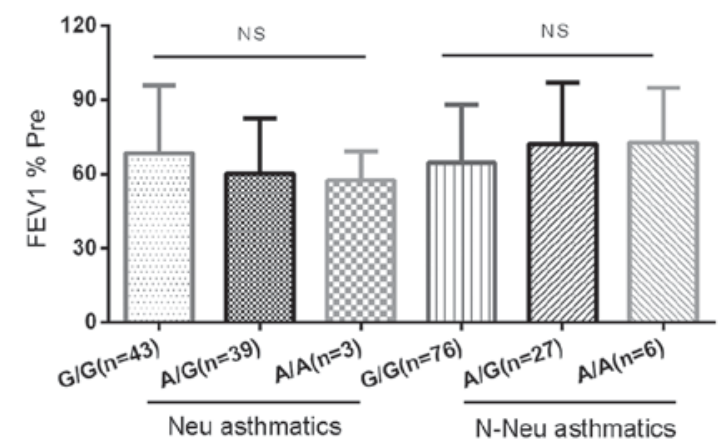

Figure 4. Association between RAGE G82S genotype and (A) plasma sRAGE level, and (B) FEV1\% Pre in NEU asthmatics (n=85) and N-NEU asthmatics $(n=109)$. RAGE, advanced glycosylation end product-specific receptor; s, soluble; FEV1\% Pre, predicted forced expiratory volume in 1 sec; NEU, neutrophilic; N-NEU, non-neutrophilic.

of airflow limitations in patients with COPD patients and asthmatic children $(24,33)$. However, Watanabe et al (11) and Zhou et al (31) observed that sRAGE levels were not associated with asthma severity in adult patients with asthma, possibly as their patients were all non-neutrophilic asthmatics. In the present study, no significant association between plasma sRAGE levels and asthma severity was observed in non-neutrophilic asthmatics. However, it was demonstrated that decreased plasma SRAGE levels were significantly associated with FEV1\% Pre in neutrophilic asthmatics, suggesting that plasma sRAGE may be a potential systemic biomarker for neutrophilic asthma severity, although not for patients with non-neutrophilic asthma.

In the present study, the sRAGE levels measured comprised all types of sRAGE, including esRAGE and cRAGE. esRAGE has been identified to be the primary soluble variant of RAGE, as demonstrated by Sukkar et al (20) in neutrophilic and non-neutrophilic asthmatics. esRAGE is generated as a splice variant of the RAGE gene. The association of the G82S variant with blood sRAGE levels has been previously reported in a number of diseases, including diabetes mellitus and COPD $(21,27,34)$. In the present study, it was demonstrated that the G82S variant was significantly correlated with plasma sRAGE levels, patients with the A allele had lower plasma sRAGE levels, and G82S variant was correlated with the severity of pulmonary dysfunction in neutrophilic asthmatics. By contrast, these findings were not observed in non-neutrophilic asthmatics and healthy controls. Furthermore, in a genome wide association study performed in a Japanese population, the RAGE G82S variant was reported to not be significantly associated with asthma susceptibility, although another single nucleotide polymorphism (rs404860) located in close proximity was associated with asthma susceptibility (35). These results raised the possibility that sRAGE levels may be determined by genetic variation in the RAGE locus, and the RAGE locus may be differentially regulated between neutrophilic and non-neutrophilic asthma patients.

sRAGE may be consumed by competitively binding to the ligands of RAGE, including HMGB1 and SAA; therefore, the levels of RAGE ligands may influence plasma sRAGE levels. Previous studies have reported that plasma and sputum HMGB1 and SAA were increased in patients with asthma and
COPD, and correlated with higher degrees of airway neutrophilia and systemic inflammation (20,25,36-38). Neutrophilic asthmatics exhibited more severe airway neutrophil inflammation compared with non-neutrophilic asthmatics, and it was hypothesized that a higher percentage of sputum neutrophils and increased RAGE ligands may be additional reasons for the decreased plasma sRAGE levels in neutrophilic asthmatics. However, no significant correlation was observed between plasma sRAGE levels and the percentage of sputum neutrophils in neutrophilic asthmatics, and it was previously reported that there were no significant differences in plasma HMGB1 levels between different asthma inflammatory phenotypes (8). These results further suggested that the G82S variant may be the primary reason for decreased plasma sRAGE levels.

It is unknown why the plasma sRAGE level was increased in non-neutrophilic asthmatics. In the present study, no significant association was observed between plasma sRAGE levels and G82S variants. It was demonstrated that the plasma sRAGE level was inversely correlated with the percentage of sputum neutrophils in non-neutrophilic asthmatics; however, a higher percentage of sputum neutrophils has been previously reported to be associated with lower plasma sRAGE levels $(20,39)$, thus it may be hypothesized that there may exist other factors which influence the sRAGE level in non-neutrophilic asthmatics. In addition to esRAGE, sRAGE has another isoform, cRAGE, which is produced via proteolytic cleavage of membrane-bound RAGE by metalloproteinases $(6,7)$. Increased expression levels of RAGE and metalloproteinases in airway and inflammatory cells may induce an increase in plasma sRAGE in asthmatic patients. However, no research into this has yet been reported.

There are a number of limitations to the present study. The sample size was relatively small. The levels of RAGE ligands were not examined, which may influence the plasma sRAGE level. In addition, the reasons for the increased plasma sR AGE level in non-neutrophilic asthmatics were not determined.

In conclusion, plasma sRAGE is decreased in neutrophilic asthmatics and is correlated with the severity of neutrophilic asthma and G82S genotype variant. The importance of and the mechanism underlying the increased plasma sRAGE level in non-neutrophilic asthmatics requires further study. 


\section{Acknowledgements}

The present study was supported by grants from the National Natural Science Foundation of China (grant nos. 81470228 and 81300029), the National Program on Key Basic Research Project (973 Program; grant no. 2012CB518203), the Natural Science Foundation of Guangdong Province (grant no. 2015A030313236), the Scientific and Technological Projects of Guangdong Province (grant no. 2016A020215117), the Medicine Foundation of Guangdong Province (grant no. A2015007), and the Science and Technology Program of Zhongshan City (grant no. 2015B1103).

\section{References}

1. Neeper M, Schmidt AM, Brett J, Yan SD, Wang F, Pan YC, Elliston K, Stern D and Shaw A: Cloning and expression of a cell surface receptor for advanced glycosylation end products of proteins. J Biol Chem 267: 14998-15004, 1992.

2. Hudson BI, Carter AM, Harja E, Kalea AZ, Arriero M, Yang H, Grant PJ and Schmidt AM: Identification, classification, and expression of RAGE gene splice variants. FASEB J 22: 1572-1580, 2008.

3. López-Díez R, Rastrojo A, Villate O and Aguado B: Complex tissue-specific patterns and distribution of multiple RAGE splice variants in different mammals. Genome Biol Evol 5: 2420-2435, 2013.

4. Yonekura H, Yamamoto Y, Sakurai S, Petrova RG, Abedin MJ, Li H, Yasui K, Takeuchi M, Makita Z, Takasawa S, et al: Novel splice variants of the receptor for advanced glycation end-products expressed in human vascular endothelial cells and pericytes, and their putative roles in diabetes-induced vascular injury. Biochem J 370: 1097-1109, 2003.

5. Maillard-Lefebvre H, Boulanger E, Daroux M, Gaxatte C, Hudson BI and Lambert M: Soluble receptor for advanced glycation end products: A new biomarker in diagnosis and prognosis of chronic inflammatory diseases. Rheumatology (Oxford) 48: 1190-1196, 2009.

6. Raucci A, Cugusi S, Antonelli A, Barabino SM, Monti L, Bierhaus A, Reiss K, Saftig P and Bianchi ME: A soluble form of the receptor for advanced glycation endproducts (RAGE) is produced by proteolytic cleavage of the membrane-bound form by the sheddase a disintegrin and metalloprotease 10 (ADAM10). FASEB J 22: 3716-3727, 2008.

7. Zhang L, Bukulin M, Kojro E, Roth A, Metz VV, Fahrenholz F, Nawroth PP, Bierhaus A and Postina R: Receptor for advanced glycation end products is subjected to protein ectodomain shedding by metalloproteinases. J Biol Chem 283: 35507-35516, 2008.

8. Hou C, Zhao H, Liu L, Li W, Zhou X, Lv Y, Shen X, Liang Z, Cai $\mathrm{S}$ and Zou F: High mobility group protein B1 (HMGB1) in asthma: Comparison of patients with chronic obstructive pulmonary disease and healthy controls. Mol Med 17: 807-815, 2011.

9. Ozseker F, Buyukozturk S, Depboylu B, Yilmazbayhan D, Karayigit E, Gelincik A, Genc S, Colakoglu B, Dal M and Issever H: Serum amyloid A (SAA) in induced sputum of asthmatics: A new look to an old marker. Int Immunopharmacol 6: 1569-1576, 2006.

10. Yang Z, Yan WX, Cai H, Tedla N, Armishaw C, Di Girolamo N, Wang HW, Hampartzoumian T, Simpson JL, Gibson PG, et al: S100A12 provokes mast cell activation: A potential amplification pathway in asthma and innate immunity. J Allergy Clin Immunol 119: 106-114, 2007.

11. Watanabe T, Asai K, Fujimoto H, Tanaka H, Kanazawa $\mathrm{H}$ and Hirata K: Increased levels of HMGB-1 and endogenous secretory RAGE in induced sputum from asthmatic patients. Respir Med 105: 519-525, 2011.

12. Buckley ST and Ehrhardt C: The receptor for advanced glycation end products (RAGE) and the lung. J Biomed Biotechnol 2010: 917108, 2010.

13. Demling N, Ehrhardt C, Kasper M, Laue M, Knels L and Rieber EP: Promotion of cell adherence and spreading: A novel function of RAGE, the highly selective differentiation marker of human alveolar epithelial type I cells. Cell Tissue Res 323: 475-488, 2006
14. Milutinovic PS, Alcorn JF, Englert JM, Crum LT and Oury TD: The receptor for advanced glycation end products is a central mediator of asthma pathogenesis. Am J Pathol 181: 1215-1225, 2012.

15. Sukkar MB, Ullah MA, Gan WJ, Wark PA, Chung KF, Hughes JM, Armour CL and Phipps S: RAGE: A new frontier in chronic airways disease. Br J Pharmacol 167: 1161-1176, 2012.

16. Park L, Raman KG, Lee KJ, Lu Y, Ferran LJ, Chow WS, Stern D and Schmidt AM: Suppression of accelerated diabetic atherosclerosis by the soluble receptor for advanced glycation endproducts. Nat Med 4: 1025-1031, 1998.

17. Vazzana N, Santilli F, Cuccurullo C and Davì G: Soluble forms of RAGE in internal medicine. Intern Emerg Med 4: 389-401, 2009.

18. Nin JW, Jorsal A, Ferreira I, Schalkwijk CG, Prins MH, Parving H, Tarnow L, Rossing P and Stehouwer CD: Higher plasma soluble receptor for advanced glycation end products (sRAGE) levels are associated with incident cardiovascular disease and all-cause mortality in type 1 diabetes: A 12-year follow-up study. Diabetes 59: 2027-2032, 2010.

19. Thomas MC, Söderlund J, Lehto M, Mäkinen VP, Moran JL, Cooper ME, Forsblo C and Groop PH; FinnDiane Study Group: Soluble receptor for AGE (RAGE) is a novel independent predictor of all-cause and cardiovascular mortality in type 1 diabetes. Diabetologia 54: 2669-2677, 2011.

20. Sukkar MB, Wood LG, Tooze M, Simpson JL, McDonald VM, Gibson PG and Wark PA: Soluble RAGE is deficient in neutrophilic asthma and COPD. Eur Respir J 39: 721-729, 2012.

21. Cheng DT, Kim DK, Cockayne DA, Belousov A, Bitter H, Cho MH, Duvoix A, Edwards LD, Lomas DA, Miller BE, et al: Systemic soluble receptor for advanced glycation endproducts is a biomarker of emphysema and associated with AGER genetic variants in patients with chronic obstructive pulmonary disease. Am J Respir Crit Care Med 188: 948-957, 2013.

22. Miniati M, Monti S, Basta G, Cocci F, Fornai E and Bottai M: Soluble receptor for advanced glycation end products in COPD: Relationship with emphysema and chronic cor pulmonale: A case-control study. Respir Res 12: 37, 2011.

23. Hoonhorst SJ, Lo Tam Loi AT, Pouwels SD, Faiz A, Telenga E, van den Berge M, Koenderman L, Lammers JW, Boezen HM, van Oosterhout $\mathrm{M}$, et al: Advanced glycation endproducts and their receptor in different body compartments in COPD. Respir Res 17: 46, 2016.

24. Iwamoto H, Gao J, Pulkkinen V, Toljamo T, Nieminen P and Mazur W: Soluble receptor for advanced glycation end-products and progression of airway disease. BMC Pulm Med 14: 68, 2014.

25. Smith DJ, Yerkovich ST, Towers MA, Carroll ML, Thomas R and Upham JW: Reduced soluble receptor for advanced glycation end-products in COPD. Eur Respir J 37: 516-522, 2011.

26. Hudson BI, Stickland MH and Grant PJ: Identification of polymorphisms in the receptor for advanced glycation end products (RAGE) gene: Prevalence in type 2 diabetes and ethnic groups. Diabetes 47: 1155-1157, 1998 .

27. Miller S, Henry AP, Hodge E, Kheirallah AK, Billington CK, Rimington TL, Bhaker SK, Obeidat M, Melén E, Merid SK, et al: The Ser82 RAGE variant affects lung function and serum RAGE in smokers and sRAGE production in vitro. PLoS One 11: e164041, 2016.

28. Gaens KH, Ferreira I, van der Kallen CJ, van Greevenbroek MM, Blaak EE, Feskens EJ, Dekker JM, Nijpels G, Heine RJ, 't Hart LM, et al: Association of polymorphism in the receptor for advanced glycation end products (RAGE) gene with circulating RAGE levels. J Clin Endocrinol Metab 94: 5174-5180, 2009.

29. Hancock DB, Eijgelsheim M, Wilk JB, Gharib SA, Loehr LR, Marciante KD, Franceschini N, van Durme YM, Chen TH, Barr RG, et al: Meta-analyses of genome-wide association studies identify multiple loci associated with pulmonary function. Nat Genet 42: 45-52, 2010.

30. Repapi E, Sayers I, Wain LV, Burton PR, Johnson T, Obeidat M, Zhao JH, Ramasamy A, Zhai G, Vitart V, et al: Genome-wide association study identifies five loci associated with lung function. Nat Genet 42: 36-44, 2010.

31. Zhou Y, Jiang YQ, Wang WX, Zhou ZX, Wang YG, Yang L and Ji YL: HMGB1 and RAGE levels in induced sputum correlate with asthma severity and neutrophil percentage. Hum Immunol 73: 1171-1174, 2012.

32. Bateman ED, Hurd SS, Barnes PJ, Bousquet J, Drazen JM, FitzGerald M, Gibson P, Ohta K, O'Byrne P, Pedersen SE, et al: Global strategy for asthma management and prevention: GINA executive summary. Eur Respir J 31: 143-178, 2008. 
33. El-Seify MY, Fouda EM and Nabih ES: Serum level of soluble receptor for advanced glycation end products in asthmatic children and its correlation to severity and pulmonary functions. Clin Lab 60: 957-962, 2014.

34. Wu TL, Tsai CC, Wang YY, Ho KY, Wu YM, Hung HC and Lin YC: The association between the RAGE G82S polymorphism, sRAGE and chronic periodontitis in Taiwanese individuals with and without diabetes. J Periodontal Res 50: 881-889, 2015.

35. Hirota T, Takahashi A, Kubo M, Tsunoda T, Tomita K, Doi S, Fujita K, Miyatake A, Enomoto T, Miyagawa T, et al: Genome-wide association study identifies three new susceptibility loci for adult asthma in the Japanese population. Nat Genet 43: 893-896, 2011.

36. Iwamoto H, Gao J,Koskela J, Kinnula V, Kobayashi H,Laitinen T and Mazur W: Differences in plasma and sputum biomarkers between COPD and COPD-asthma overlap. Eur Respir J 43: 421-429, 2014.
37. Bozinovski S, Hutchinson A, Thompson M, Macgregor L, Black J, Giannakis E, Karlsson AS, Silvestrini R, Smallwood D, Vlahos R, et al: Serum amyloid a is a biomarker of acute exacerbations of chronic obstructive pulmonary disease. Am J Respir Crit Care Med 177: 269-278, 2008.

38. Ferhani N, Letuve S, Kozhich A, Thibaudeau O, Grandsaigne M, Maret M, Dombret MC, Sims GP, Kolbeck R, Coyle AJ, et al: Expression of high-mobility group box 1 and of receptor for advanced glycation end products in chronic obstructive pulmonary disease. Am J Respir Crit Care Med 181: 917-927, 2010.

39. Yerkovich ST, Chang AB, Carroll ML, Petsky HL, Scrivener G and Upham JW: Soluble receptor for advanced glycation end products (sRAGE) is present at high concentrations in the lungs of children and varies with age and the pattern of lung inflammation. Respirology 17: 841-846, 2012. 